en Herrera del Duque (Badajoz) y Guadalupe, y de Cyaneus en Villar del Pedroso (Cáceres). Bien sea un pintor toledano o extremeño, de lo que no cabe duda es de que se trata de un artista de cierta calidad, vinculado al círculo de Morales y al que no es ajeno el ambiente pictórico toledano contemporáneo y, a propósito de ello queremos citar el nombre de fray Juan Moreno, autor de una cena en el convento toledano de San Clemente, y cuyo rostro de San Juan Evangelista es similar al de la Virgen de la Asunción.

No cabe duda de que la Magdalena de Lille debió salir de España bien durante las guerras napoleónicas o cuando la desamortización ${ }^{17}$.

Isabel Mateo Gómez Dpto. de Arte del C.S.I.C.

\title{
LA HIEROGLYPHICA Y EL NACIMIENTO DE VENUS
}

De la pintura

Sin duda a Botticelli se le debe el honor de ser el primero en pintar cuadros mitológicos monumentales que en tamaño competían con el arte religioso de la época. Entre sus argumentos, los más afamados vienen a ser las dos pinturas (hacia 1478) hoy custodiadas en los Uffizi y que conocemos como La Primavera y el Nacimiento de Venus, fábulas que proceden muy probablemente de la Villa di Castello de la que era propietario Lorenzo de Pierfrancesco, primo de Lorenzo de Médici y mecenas del maestro pintor. Las dos pinturas, como analizan importantes historiadores como Gombrich y Panofsky parecen responder a un concreto programa argumental de claro sentido platónico y que explican la idea del Amor a través de la Venus Humanitas y la Celestis, es decir, el sentimiento humano y el contemplativo, comportamientos generados por Dios y por lo tanto, buenos en sí mismos.

De la placenta marina como gestación del espíritu: El Nacimiento de Venus (fig.1).

El mar tuvo una importancia extraordinaria como medio de vida, las mitologías lo entendieron como algo más, como placenta de la que surgió la diosa más perfecta de cuantas se dieron cita en el Olimpo: Venus. Así se narra en la fábula clásica, pues leyendo a Hesíodo en su Teogonía sabemos que Urano (Cielo) se unió con Gea (Tierra), y temiendo el poder de los hijos que ambos tuvieron, los asesinaba estrellándolos contra la propia madre o tierra. Gea pidió a sus hijos venganza, venganza que realizó el pequeño de ellos, llamado Cronos o Saturno. Así nos lo cuenta el griego:

Madre, en verdad te prometo llevaré a cabo esta venganza. Efectivamente, ya no tengo respeto a nuestro padre, porque él fue quien primero meditó un designio cruel.

Habló así, y la gran Gea se regocijó en su corazón. Y lo escondió en una emboscada, y le puso en la mano la hoz de dientes cortantes, y le confió todo su designio. Y llegó el gran Urano, trayendo la noche, y se tendió sobre Gea por entero y con todas sus partes, lleno de un deseo de amor. Y fuera de la emboscada, su hijo le cogió la mano izquierda y con la derecha

\footnotetext{
${ }^{17}$ No queremos sustraernos a la tentación de encontrar cierto parecido entre el rostro de la Magdalena de Lille con el de María de Portugal, primera esposa de Felipe II, quien pasa por Badajoz en 1543, camino de Salamanca, para contraer matrimonio con el monarca. (figs. 13-14).
}

AEA, LXXVI, 2003, 303, pp. 301 a 329 
asió la hoz horrible, inmensa de dientes cortantes. Y cercenó rápidamente las partes genitales de su padre, y las arrojó detrás de sí. $Y$ no se escaparon en vano de su mano.

Gea recogió todas las gotas sangrientas que manaron de la herida; y transcurridos los años, parió a las robustas Erinnias y a los grandes Gigantes de armas resplandecientes, que llevan en la mano largas lanzas; y a las ninfas que en la tierra inmensa son llamadas Melias.

$Y$ las partes que había cercenado, Cronos las mutiló con el acero, y las arrojó desde la tierra firme al mar de olas agitadas. Flotaron mucho tiempo sobre el mar, y del despojo inmortal brotó blanca espuma, y de ella salió una joven. Y primero fue llevada ésta hacia la divina Citerea. Y de allí a Cipros, la rodeada de olas.

Abordó a tierra la bella y venerable diosa, y la hierba crecía bajo sus pies encantadores. $Y$ fue llamada Afrodita, la diosa de hermosas bandeletas, nacida de la espuma, y Citerea por los dioses y por los hombres. Afrodita, porque abordó a Citeres; y Ciprigenia, porque arribó a Cipros, la rodeada de olas, y Filomedea, porque había salido de las partes genitales.

El texto explica la pintura de Botticelli y en este sentido el título de la composición debería responder a la llegada de Venus a Chipre y no al propuesto por Vasari como El Nacimiento de Venus. Todo se explica por cuanto la Iglesia no veía con buenos ojos representar una castración como argumento plástico.

Retomando la pintura observamos como se da cuenta de un suceso posterior al nacimiento de Venus tras fecundar el semen de Urano las aguas del mar, su llegada a Chipre. Pero de una u otra manera sabemos que esta Venus no tiene madre. Es la llamada por Platón, Urania o Celeste, para diferenciarla de la popular o Humanitas que nació de Júpiter y Dione. Para los platónicos se explicaban así los dos amores: el primero superior o espiritual, pues Venus nació del cielo y por ello se dirige a la inteligencia, mientras que el segundo es claramente sensual y popular. Así nos lo dice Platón en el Banquete:

Es sabido que sin el Amor no habría una Venus; si ésta fuera solamente una no habría más que un Amor, pero puesto que hay dos Venus, tiene que haber también dos Amores. ¿Quién duda de que hay dos Venus? La una, la mayor, hija del Cielo y que no tiene madre, es la que nosotros denominamos Venus celestial; la otra más joven es hija de Júpiter y de Dione y la llamamos Venus popular, se deduce que de los dos Amores que son los ministros de estas dos Venus, hay que llamar al uno celestial y al otro popular (Banquete 179e).

El neoplatónico Ficino, nos dice en De Amore que el nacimiento de Venus sobre el mar ha de entenderse como la liberación de la madre o materia y por lo mismo es una referencia directa al llamado amor intelectual, pues la mente es ajena a todo trato con la materia corporal. El comentarista de Platón continúa precisando que el amor referido por la Venus popular o netamente sensual, es inferior, pero también bueno. En parecidos términos se manifiesta el español León Hebreo en sus Diálogos de Amor. En este sentido trata de resumir Gombrich el argumento final de la composición de Botticelli ${ }^{1}$ : «las dos pinturas forman parte de un único programa inspirado en la filosofía neoplatónica que tanta fuerza tuvo en la corte florentina del Magnífico: La Primavera en su relación con la Humanitas y el Nacimiento de Venus con el sentido explícito de lo contemplativo, del mayor conocimiento y comunión con la Idea celeste. Gombrich fundamenta su lectura en el texto de Ficino ${ }^{2}$ :

\footnotetext{
1 Gombrich E., Imágenes Simbólicas., Madrid 1983.

2 Ob. cit., pág. 122.
} 


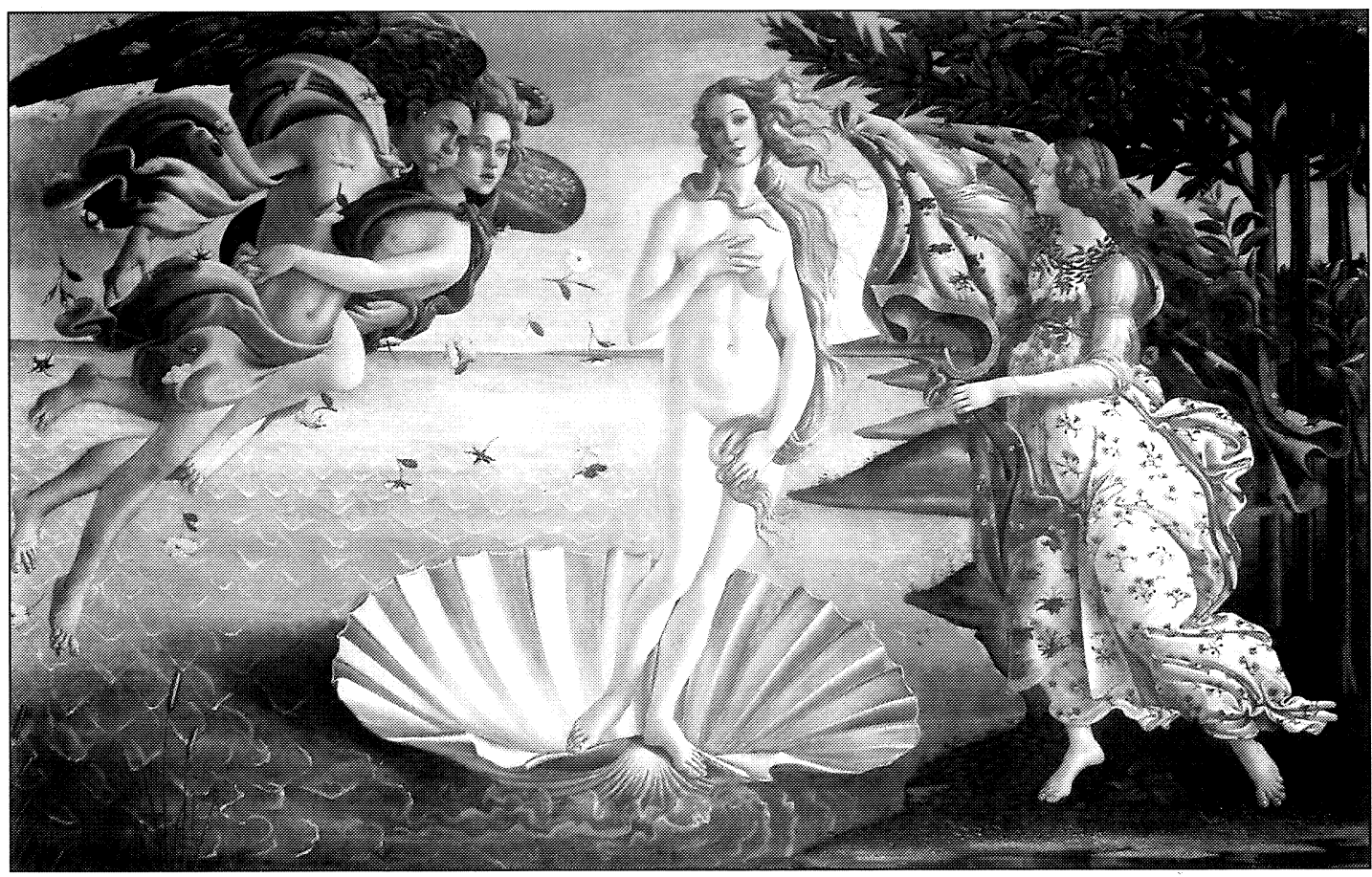

1

2

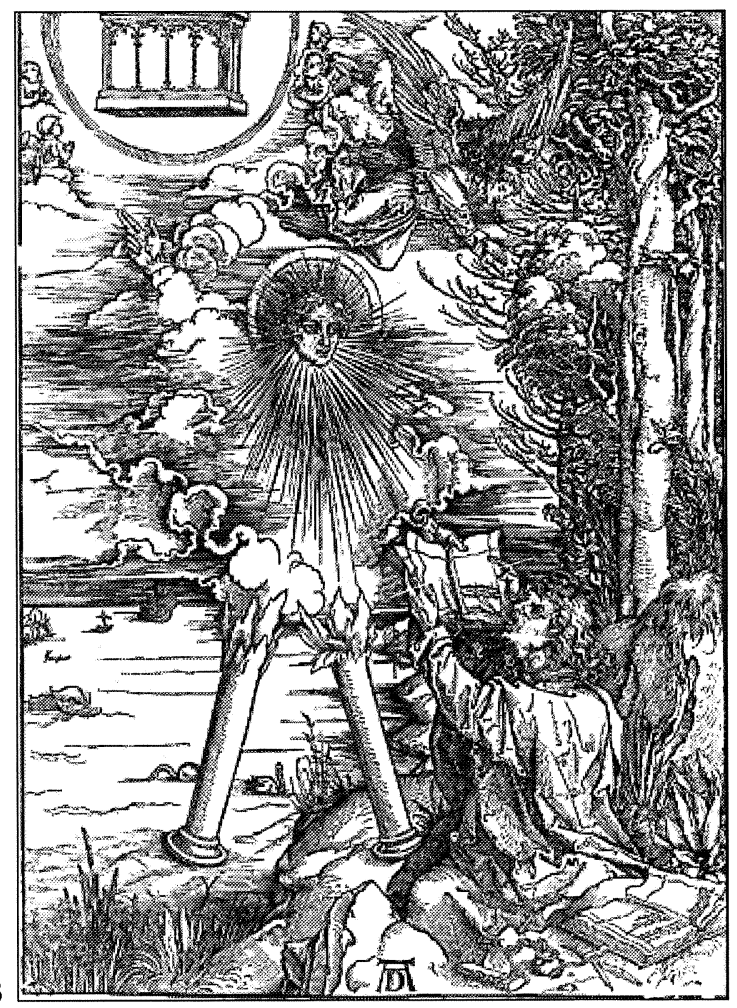

Fig. 1. Botticelli: Nacimiento de Venus. Florencia. Museo de los Ufizzi.

Fig. 2. Hieroglyphica Horapolo.

Fig. 3. Alberto Durero: San Juan devorando el libro.

AEA, LXXVI, 2003, 303, pp. 301 a 329 
La historia narrada por Hesiodo en la Teogonía que dice que Saturno castró al Cielo y arrojó sus testículos al mar, de cuya agitada espuma nació Venus, tal vez debiéramos entenderla referida a la potencial fecundidad de todas las cosas latentes en el primer principio. Esto lo bebe el espíritu divino y lo despliega primero en su interior, tras de lo cual lo vierte en el alma y la materia, que se llama mar, por causa del movimiento, tiempo y humor de la generación. En cuanto el alma ha sido fertilizada de esta manera, crea la Belleza en su interior; por un movimiento ascendente de conversión hacia las cosas suprainteligibles; y por un movimiento descendente da a luz el encanto de las cosas sensibles en la materia. A esta conversión en Belleza y a su nacimiento del alma se le llama Venus. Y como en todos los aspectos y en la misma generación de la Belleza hay placer, y como toda generación proviene del alma, que se llama Venus, muchos piensan que Venus misma era Placer.

En consecuencia, la pintura nos traduce su sentido. Así como Venus, la máxima belleza, nació del cielo fecundando el mar o medio informe, así la idea llega del cielo al hombre, a su medio informe que es la mente y quedando fecundada lleva a la generación de la máxima Belleza y del sumo Bien, es decir, a la Idea que es lo superior por ser el máximo conocimiento.

\section{De los Hieroglyphica como síntesis semántica en la pintura}

Hacia el año 1422 llegó a la ciudad del Arno el texto de Horapollo conocido por los Hieroglyphica. La trascendencia de este suceso para los pensadores y artistas fue, a juicio de los estudiosos, notoria. Nace con ello un vocabulario visual y semántico que, fundamentado en el antiguo Egipto, justificaba su validez, universalidad y fundamento teórico. No insistimos en este apartado al que ya dedicamos nuestro estudio en la edición en castellano de los Hieroglyphica ${ }^{3}$.

Curiosamente la pintura de Botticelli no escapa a la moda de su tiempo y el jeroglífico se convierte en un medio visual que resume el sentido final que se desea en la composición.

Si observamos la pintura, repararemos en la zona inferior bajo la figura del viento Céfiro, se disponen varios juncos. Este aspecto me llamó la atención por cuanto el junco precisa de humedad pero por lo general no hunde su tallo en el medio acuático. Analizando las ideas e imágenes que nos ofrece Horapollo, leemos que por el junco se desea representar las letras egipcias ya que los egipcios escriben con el junco y además añade que remite a la idea de límite: porque el que aprende las letras ha llegado a un puerto seguro de vida, sin errar ya por los males de la existencia (fig. 2). El tratado desea explicar por este elemento la imagen del hombre sabio, del ser elevado en la jerarquía social por el cultivo de las letras. En este sentido, el contenido del jeroglífico es coincidente con el texto de Ficino en su Epistolarium y que Gombrich propone como fuente literaria en la pintura de Botticelli. El erudito florentino resume su carta a Pierfrancesco con estas palabras: En conclusión pues, y resumiendo, si dispones de tal manera los signos celestiales y tus dotes saldrás indemne de todas las asechanzas de la fortuna y, con la protección divina, vivirás feliz y libre de cuitas ${ }^{4}$.

Encontramos que por el junco se desea remitir al conocimiento, al conocimiento superior que permite trascender el mundo meramente material. Esta es la idea que Gombrich quiere justificar en Ficino y que el neoplatónico nos explica en sus textos como Botticelli lo hace en

\footnotetext{
3 J.M. González de Zárate., Los Hieroglyphica de Horapollo., Madrid 1991.

${ }^{4}$ Gombrich E., Imágenes Simbólicas., pág. 74.
}

AEA, LXXVI, 2003, 303, pp. 301 a 329 
su pintura. Por el conocimiento se debe entender la fecundidad del cielo en la mente, es decir, el nacimiento del saber como el sumo Bien y la suma Belleza que permite al hombre superar el medio sensual y humano para llegar al mundo de las Ideas, a Dios.

Valeriano, en el siglo xvI, recogió el mismo título en su tratado que Horapollo, Hieroglyphi$c a$, y nos dice, siguiendo los mismos contenidos, que el junco remite al hombre estudioso, al saber (Hier. LVII. XVII). Señala Panofsky que Durero ilustró, a instancias del humanista Pirckheimer, los Hieroglyphica de Horapolo y en base a estas descripciones semánticas compuso el Arco de Maximiliano. Hemos de notar como en una de sus estampas para la serie sobre $E l$ Apocalipsis, concretamente la de San Juan devorando el libro (fig. 3) (que sin duda remite al conocimiento de lo superior, de lo celeste), aparece de igual manera el junco, sin duda como elemento visual e iconográfico de un espíritu elevado, sumido el conocimiento de lo trascendente.

Se amonesta, en consecuencia, con el argumento dirigido a Pierfrancesco, al hombre en general, que entre las propuestas de su existencia la superior es aquella que cultiva el conocimiento, pues lleva el espíritu a la sabiduría, al conocimiento de Dios.

Jesús María GonZÁlez de ZÁRATE Universidad del País Vasco

\section{NOTICIAS SOBRE LAS OBRAS DE ALONSO CANO EN MADRID: EL CRISTO DE LA HUMILDAD DE LA REAL CONGREGACIÓN DEL SANTO CRISTO DE SAN GINÉS ${ }^{1}$}

A pesar de los nuevos datos que están siendo publicados, y de la considerable importancia de la etapa madrileña de Alonso Cano, aún son muchas las dudas en torno a la actividad del granadino en la Corte. José Manuel Cruz Valdovinos ya recalcó la importancia de la figura del conde-duque de Olivares, gracias a la cual, Cano entraría en contacto con un importante círculo de funcionarios al servicio de la Corona ${ }^{2}$. Poco a poco se ha ido conociendo y documentando la existencia de una clientela del artista dentro de ese grupo, con personajes tan relacionados con el Valido como José González, abogado particular del propio Conde-Duque; Sebastián Vicente, tesorero del Buen Retiro; José de Cisneros, pagador general de Galeras; Juan de Vallecas, escribano mayor de Millones....

En este sentido creemos poder contribuir a completar un poco más el círculo cortesano en el que se movió el granadino a través de la documentación encontrada en el Archivo Histórico de Protocolos de Madrid, que relaciona el cuadro del Cristo de la Humildad de Alonso Cano de la Real Congregación del Cristo de San Ginés de Madrid con doña Francisca Ladrón de Guevara, viuda de don Pablo Antonio Suárez, juez de quiebras de rentas reales de Carlos II e hija del gobernador don Martín Ladrón de Guevara.

La primera referencia que relaciona el lienzo de Alonso Cano con la citada doña Francisca Ladrón de Guevara, es la que aparece en la memoria de sus bienes que incluyó su marido, don Pablo Antonio Suárez, en el testamento cerrado que firmó en Madrid el 12 de agosto de 1679 ante el escribano Pedro Alvarez de Peralta, donde dejaba dispuesta su última voluntad, entierro,

\footnotetext{
' Al transcribir documentos se han seguido las siguientes normas paleográficas: desarrollo de las abreviaturas indicándolo mediante paréntesis, modernización de puntuación, acentos y mayúsculas, utilización de corchetes para salvar palabras de difícil lectura y de dos líneas oblicuas para señalar el cambio de folio.

2 J. M. Cruz Valdovinos, «Varia canesca madrileña» en Archivo Español de Arte, 231, (1985), p. 286.
}

AEA, LXXVI, 2003, 303, pp. 301 a 329 